\title{
AGGREGATE JOB DESTRUCTION AND INVENTORY LIQUIDATION
}

\author{
Robert E. Hall
}

Working Paper 6912

http://www.nber.org/papers/w6912

\author{
NATIONAL BUREAU OF ECONOMIC RESEARCH \\ 1050 Massachusetts Avenue \\ Cambridge, MA 02138 \\ January 1999
}

This research was supported by the National Science Foundation under grants SBR-9410039 and SBR9730341, and is part of the research program on Economic Fluctuation and Growth of the NBER. I am grateful to Éva Nagypál for helpful comments and assistance. The views expressed here are those of the author and do not reflect those of the National Bureau of Economic Research.

( 1999 by Robert E. Hall. All rights reserved. Short sections of text, not to exceed two paragraphs, may be quoted without explicit permission provided that full credit, including ${ }^{\odot}$ notice, is given to the source. 
Aggregate Job Destruction and Inventory Liquidation

Robert E. Hall

NBER Working Paper No. 6912

January 1999

JEL No. E24

\begin{abstract}
In a recession, jobs are destroyed and inventories are liquidated. I concentrate on the intertemporal mechanisms that result in economy-wide job destruction and inventory runoffs. Forces that raise the real interest rate -- especially temporarily -- also cause destruction and runoffs. I consider a model where the job destruction decision is made efficiently, will full consideration of the search costs imposed on discharged workers. I also consider a model of inefficient job destruction, where employers discharge workers who are paid fixed wages as long as they are employed. The impulse response functions for these models resemble those found in data for the United States. A shock that causes a jump in the expected real interest rate results in an immediate spike of job destruction and inventory liquidation, followed by a declining pattern of additional destruction and runoff.
\end{abstract}

Robert E. Hall

Hoover Institution

Stanford University

Stanford, CA 94305

and NBER

hall@hoover.stanford.edu 


\section{Introduction}

From time to time, the economy enters a recession and jobs are destroyed simultaneously in all of the important sectors of the economy. At the same time, firms liquidate inventories. What mechanism causes job losses and inventory runoffs throughout the economy? A decline in demand seems a natural part of the answer. But what does it mean for demand to fall for all the products in the economy? What relative price adjusts to keep markets in equilibrium if demand falls? The answers lie in intertemporal economics. Demand for products delivered today can rise while demand for products tomorrow falls, just as demand for potatoes can rise while demand for rice declines. The relative price that adjusts to clear the market for products today against products tomorrow is the interest rate. Accordingly, this paper explores the relation between the interest rate and job destruction.

The data show that recessions are often preceded by sharp increases in real interest rates. This paper builds an intertemporal model to mimic this relationship. In the model, firms face the question of whether to continue the operation of marginal plants and other productive units or to shut them down. An increase in the interest rate shifts the decision toward shutdown because the firm avoids the immediate costs of holding inventories and other capital, whereas the foregone profit lies in the future. The burst of job destruction and inventory decumulation that occurs during the sharp part of the typical contraction results from decisions to shut down units in firms throughout the economy.

My focus in this paper is primarily on the interest-rate-job-destruction mechanism and less on the source of demand shifts and accompanying changes in the interest rate. The model describes the responses of workers and firms to 
exogenous changes in interest rates. The reason is that the large increases in interest rates that have actually occurred in the U.S. economy in the past 30 years seem to have a monetary origin, at least in large part. Because there is no consensus on the proper model of the real effects of nominal driving forces, I enter this difficult territory only in a tentative way in interpreting the empirical relation between the interest rate, job destruction, and inventory decumulation.

The model considers productive units. A unit may be a plant, an operation within a plant, or the activities of a single worker. A unit is shut down when its continuation value falls below its liquidation value. The unit is closed and liquidated and the workers enter the labor market to make new matches. The two most prominent characteristics of recessions_-bursts of job loss and high rates of inventory liquidation - are the result of the same mechanism, in this view. The role of shutdown decisions in inventory runoffs has not previously been explored, to my knowledge. It is well known, however, that shutdowns of various types account for a large fraction of the burst of job destruction that occurs at the beginning of a recession (Davis, Haltiwanger, and Schuh [1996]).

An essential ingredient in the model is explicit consideration of unemployment and the time required to place workers in new jobs after earlier jobs are destroyed. There has been an explosion of activity in the theoretical macroeconomic literature incorporating unemployment—see Hall [1998a] for many references. Almost without exception, modern research adopts the view of Diamond [1982a] and Mortensen [1982] that unemployment is a bilateral search process. Their framework also provides a clear way to think about job destruction-the match between worker and firm ends when there is no longer any joint surplus from the relationship.

The Diamond-Mortensen view presumes the efficiency of separationsjobs end only when separation is in the joint interest of worker and firm. A shutdown imposes substantial periods of foregone work on the job-losers and it 
may require investment to occur elsewhere in the economy to create replacement jobs. Efficient decisions balance all of the positive and negative effects of a shutdown on the firm and the workers. The negatives are the lost output from the unit that is shut down and the resources needed to equip the replacement jobs (or, equivalently, the diminution in productivity of other workers when newly hired workers are squeezed onto existing facilities). The positives are the liquidation value of the old unit and the higher level of output in a new unit, after the time for the displaced workers to return to work. The first model in this paper assumes full efficiency in job destruction decisions.

But the factual basis for efficient separation has yet to be established. There are two reasons to question the assumption. First, the Diamond-Mortensen employment relationship is inefficient with respect to the formation and preservation of match-specific capital. Second, there are profound issues of the observability of the information required for efficient separation. Consequently, I also consider a related framework in which shutdowns are not necessarily bilaterally efficient between employer and worker. In that framework, firms make unilateral shutdown decisions guided by the profit they earn under simple fixedwage contracts with their workers. A shutdown sacrifices the present value of profit from the unit - the difference between its revenue and the contractual wage payments made to workers. The benefit of a shutdown is the avoided carrying costs of the capital tied up in the unit. The model implies much higher volatility of job destruction for given volatility of the real interest rate than the model with efficient separations.

The paper presents empirical evidence on the joint behavior of job destruction and inventory liquidation, on the one hand, and the discount rate on the other hand. The variables I consider are the Davis-Haltiwanger [1990] measure of job destruction, the change in employment, the change in inventories, and the 6-month commercial paper rate stated in real terms. In a 9-industry 
breakdown of U.S. industries, I find a strong positive relation between job destruction and the expected real rate and a strong negative relation between employment growth and the expected real rate. In three of the four industries that hold inventories (durables and wholesale and retail trade), there is a positive association between the expected real rate and inventory liquidation (nondurables are the exception).

\section{Economics of the Shutdown Decision}

The shutdown decision fits into the general framework of research on the employment contract. That research has two branches relevant for this issue. The older branch-currently inactive-includes Hashimoto and $\mathrm{Yu}$ [1980], Hart [1983], Hall and Lazear [1984], and Kahn and Huberman [1988]. Separation or shutdown decisions are made unilaterally by the worker or firm, subject to a fixed-wage contract. The discussion of the design of the contract is strongly influenced by the literature on mechanism design derived from Mirrlees's [1971] famous paper.

Modern thinking about the employment relationship, as reflected in Diamond [1982a and b], Mortensen [1982], Ramey and Watson [1997], Caballero and Hammour [1996a, 1996b, and 1997], and hundreds of other papers, insists that strategic relationships, such as the employment relationship, satisfy the criterion of subgame perfection. Parties will not adhere to terms such as fixed wages that they can negotiate around later to their mutual benefit. An employment contract does not necessarily guide the relationship as stated, but only establishes the threat points for a subsequent bilateral bargaining problem. The Nash solution to that bargaining problem-where the parties split the joint surplus from their 
relationship_-governs the outcome. For further discussion of the relation between the two branches, see Hall [1995, 1997, and 1998a].

The fixed-wage view leads naturally to the conclusion that inefficient shutdowns can occur. The firm takes the wage as the value of the workers' time; if the wage overstates that value, the firm may shut a unit down despite the resulting reduction in joint value. Firms pay the lowest wage needed to attract workers in the first place and stick to that wage. In making decisions about shutdowns, firms treat the wage as a cost. These contracts have the substantial advantage of preventing workers from appropriating the investments that firms sink in their relations with their workers. Firms enjoy the full benefits of those investments and therefore invest up to the social optimum. ${ }^{1}$

The modern view holds that fixed-wage contracts-whatever their merits - fail the elementary test of subgame perfection. The parties have the power to make Pareto improvements after random realizations occur and they cannot be expected to fail to exploit the power. The source of the power is the requirement that the employment contract gives both workers and firms the unilateral rights to end the relationship. No practical contract can be designed without these rights. The exercise of these rights defines the threat points of a bargaining situation that exists throughout the relationship. In each period, the parties divide the joint surplus-the difference between the continuation value and the combined shutdown values-in specified proportions. Only when the joint surplus reaches zero does shutdown actually occur, and shutdown is efficient in this case.

As Mortensen [1982] pointed out in his original analysis, and recent authors in this branch of the literature, such as Hosios [1990] and Caballero and

\footnotetext{
${ }^{1}$ Caballero and Hammour [1996a, 1996b, 1997] stress the inefficiencies of appropriability but assume that fixed-wage contracts cannot solve the problem, because of renegotiation.
} 
Hammour [1997] have stressed, match-specific investments are inadequately compensated in the surplus-sharing setup, unless they are made jointly.

I will not try to resolve this major watershed issue in the modern theory of the employment relationship. I develop two related models with efficient and inefficient separations. My empirical results do not rest on assumptions one way or the other about the efficiency of the employment relationship.

\section{Inventories}

A key feature of the view of recessions developed in this paper is that the burst of inventory disinvestment that occurs during the sharpest part of the typical contraction is the result of a process that also causes job destruction. Employment changes and inventory investment are in fact closely linked, as Figure 1 shows. A two-sided distributed lag relation between manufacturing inventory investment (as a fraction of total GDP) and employment growth accounts for most of the cyclical behavior of inventories.

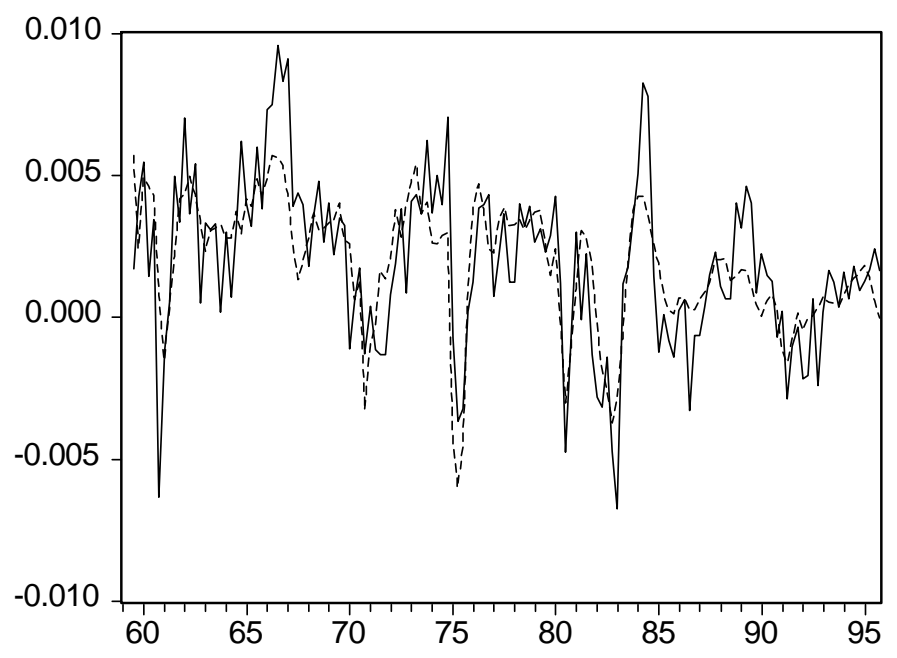

Figure 1. Relation between Manufacturing Inventory Investment (as a Percent of GDP, Solid Line) and a Distributed Lag of Employment Growth (Dashed Line) 


\section{IV.The Model with Efficient Separation}

This section develops a simple model of recessions where an increase in the interest rate triggers a burst of job destruction. In the model, new productive units are created when a searching worker is matched to a production opportunity. Initially, the worker produces one unit of output per period, when equipped with capital formed from $\gamma$ units of output. With probability $\pi$ each period, the productive opportunity degrades so that it produces only a fraction $\omega<1$ of its earlier number of units of output with the same inputs. After $i$ instances of random degradation, productivity is $\omega^{i}$. The single economic decision in the model is whether to continue a match.

There are $n_{t}$ employed workers and $u_{t}$ unemployed job searchers. At the beginning of the period, the decision is made whether to continue the employment of each worker in a lower-productivity job or to shut the unit down and release the worker into search. Searching workers have a probability $\phi$ of finding a new, high-productivity match each period (there are no congestion externalities).

Let $d_{t}$ be the volume of job destruction - the number of workers released as a result of shutdowns. Then workers transit among states as follows:

$$
\begin{gathered}
n_{t}=n_{t-1}+\phi u_{t-1}-d_{t}, \\
u_{t}=\mathbf{D}_{\phi} \mathbf{y}_{-1}+d_{t},
\end{gathered}
$$

To describe the decision about continuation versus shutdown, I let $J_{i, t}$ be

the value associated with a match with productivity $\omega^{i}$ and $U_{t}$ be the value associated with unemployment and job search. The discounting of future returns 
in forming these values is governed by an exogenous random variable $r_{t}$ that obeys

$$
\rho(L)
$$

where $\varepsilon_{t}$ is iid normal. The decision-making unit chooses its decision rule to maximize

$$
E_{0} e^{-\sum_{s=0}^{t-1} r_{s}} z_{t}
$$

where $z_{t}$ is receipts at time $t$ measured in units of goods. $E_{0}$ is the expectation as of time 0 and $e^{-\sum_{s=0}^{t-1} r_{s}}$ is the stochastic discounter in the sense of Kreps [1981] and Hansen-Jagannathan [1991]; it is log-normal.

The current values are related to discounted future values according to

$$
\begin{gathered}
\left.J_{i, t}=\max \left\{\mathbf{E}_{t}\left[e^{-r_{t}} \mathbf{Q}^{i}+\boldsymbol{D}_{-\pi} \mathbf{g}_{, t+1}+\pi J_{i+1, t+1}\right]\right], \gamma+U_{t}\right\}, \text { and } \\
U_{t}=E_{t}\left\{{ }^{-r_{t}}\left[\boldsymbol{D}_{\phi} \mathbf{g}_{t+1}+\phi \mathbf{d}_{, t+1}-\gamma \mathbf{i}\right]\right\} .
\end{gathered}
$$

In equation 4.6, the firm and worker compare their joint continuation value, $\left.E_{t}\left[e^{-r_{t}} \mathbf{Q}^{i}+\mathbf{D} \pi \mathbf{g}_{t+1}+\pi J_{i+1, t+1}\right]\right]$, to their breakup value, $\gamma+U_{t}$, and act accordingly. The avoided investment cost, $\gamma$, is key. By liquidating some 
inventories and not making new investments in inventories and other capital, current outlays can be avoided or cash raised by shutting down. ${ }^{2}$

In the steady state with a constant interest rate, $r_{t}=\delta$, workers remain in their jobs until they have progressed through a critical number of productivity degradations, $k$. The steady-state values of new jobs, $J_{0}$ and job search $U$ are the solutions to

$$
\begin{gathered}
J_{0}=\frac{1}{r+\pi} \sum_{i=0}^{k-1} \boldsymbol{F}_{r+\pi}^{\pi} k^{i}\left\langle\omega^{i+} \boldsymbol{F}_{r+\pi}^{\pi} k_{k}^{k} \boldsymbol{D}_{+U} \mathbf{g}\right. \\
U=\frac{\phi}{r+\phi} \mathbf{b}_{-\gamma} \mathbf{s}
\end{gathered}
$$

Here $r=e^{\delta}-1$ is the one-period steady-state interest rate. The value associated with being in a new job is the present value of its future output plus the present value of the successor job. The value associated with job search is the present value of the new job after the period of search.

The cutoff value, $k_{s}$ is the one for which the corresponding search value satisfies

$$
\omega^{k} \leq r \mathbf{D}+U \mathbf{G} \omega^{k-1}
$$

\footnotetext{
${ }^{2}$ In principle, there is a third option, to continue the affiliation of the worker and the firm, but without working or holding capital (labor hoarding). The condition for this to occur is $\bigoplus e^{-r_{t}} j \gamma>\omega^{i}$. But the actual values never come close to this condition in practice.
} 
that is, current output $\omega^{k-1}$ exceeds the opportunity cost of the alternative activity, search, $r \boldsymbol{Q}+U$ ? at this level of productivity, but will fall short after the next degradation lowers productivity to $\omega^{k}$.

In the steady state, the fraction of workers unemployed is

$$
u=\frac{\pi}{k \phi+\pi}
$$

The model illustrates some simple points about reorganization and the cleansing effects of recessions. The model considers both organizational and physical capital. The organizational capital is formed when workers find highproductivity jobs. Job destruction results in the formation of new organizational capital-as workers are rematched, they start in jobs that are more productive at first than were their old jobs. The steady state involves an optimal mix of physical capital and organizational capital. The steady state could be made more intensive in organizational capital by choosing a lower cutoff productivity state, $k$, implying a higher cutoff level of productivity. Unemployment would be higher, as shown by equation 4.9. In that case, the average level of productivity of employed workers would be higher and physical capital would be lower (capital per worker is $(1-$ ). But that organizational capital is not worth its investment cost, that is, the search time of workers. So additional cleansing does not pay off and does not occur in the steady state. A temporarily high interest rate can cause job destruction and subsequent formation of new organizational capital. The cleansing effect then more than offsets the search costs.

The effects of an increase in the interest rate in the model are ambiguous. Job destruction is part of the process of investing in organizational capital. On this account, one would expect a higher interest rate to go with lower job destruction. Times of high interest rates are times of scarce resources when it is appropriate to 
defer all types of investment, including the formation of organizational capital. On the other hand, job destruction is also part of the process of disinvesting in the capital resources tied up in low-productivity jobs. When the interest rate rises above a critical level, it pays to release these resources immediately rather than to retain them to make future production possible. The capital/labor ratio $\gamma$ has a key role. For lower levels of $\gamma$, the role of organizational capital dominates and a higher interest rate lowers job destruction. For higher levels, the role of physical capital dominates and a higher interest rate stimulates job destruction.

I will use the model to calculate the response functions of job destruction to innovations in the real interest rate, using the following parameter values:

$\begin{array}{lll}\gamma & \text { Inventory-sales ratio } & 6 \\ \delta & \text { Mean of interest rate } & 0.06 \\ \rho(L) & \text { Autoregressive process for the interest rate } & 1-.9 L \\ \sigma_{\varepsilon} & \begin{array}{l}\text { Standard deviation of innovation to interest } \\ \text { rate }\end{array} & .01 \\ \phi & \begin{array}{l}\text { Job-finding rate } \\ \pi\end{array} & 0.2 \\ \omega & \begin{array}{l}\text { Transition probability from high to low } \\ \text { productivity }\end{array} & 0.2 \\ & \begin{array}{l}\text { Relative productivity of match after } \\ \text { degradation compared to before }\end{array} & 0.99\end{array}$

These values are illustrative and are not calibrated to empirical findings except in the roughest way.

Details about the calculation of the impulse response functions are in an appendix available from the author. ${ }^{3}$ Briefly, I iterate backwards over equations 4.5 and 4.6, treating the variables $J$ and $U$ as functions of $r_{t-1}$. This process converges to stationary functions, which then yield a policy function that tells, for each level of productivity, whether or not the worker should separate as a function 
of $r_{t-1}$. Then I simulate forward, making a random draw for the innovation in the interest rate each period, determining which productivity categories yield separations. I also determine the volume of new hires from among the existing unemployed and the movements of workers through productivity degradation. To measure the impulse response function, I perform 10,000 pairs of simulations over 100 periods. The first is performed as just described. The second uses the same set of interest-rate innovations, except that the innovation in period 51 is taken to be one standard deviation larger than before. I compile the difference between the amounts of job destruction in each pair. The impulse response function is the average of the difference over the 10,000 pairs.
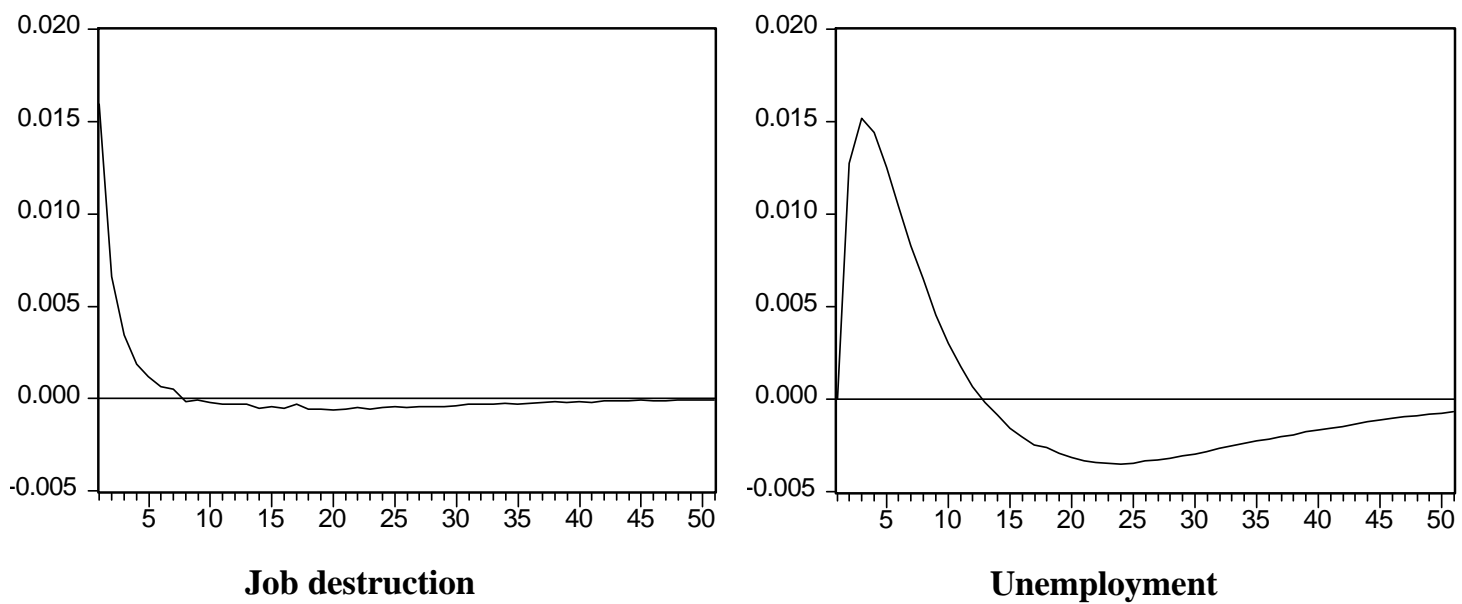

Figure 2. Impulse Response Functions of Job Destruction and Unemployment to a Real Interest Rate Innovation

Figure 2 shows the impulse response functions calculated in this way for job destruction and unemployment in the model. Job destruction jumps to a peak as soon as the shock to the real interest rate occurs. Destruction subsides over the

\footnotetext{
${ }^{3}$ http://www.stanford.edu/ rehall/
} 
next few periods. Unemployment rises quickly but not immediately to a peak, and then gradually descends. The dynamics share important properties with actual recessions - the sharp spike in job destruction accompanied by a high interest rate followed by a prolonged period of above-normal unemployment.

Both impulse response functions drop below zero about 10 to 15 periods after the shock. The model has the property of concentration that I describe in a companion paper (Hall [1998b]). Once a shock has displaced workers and caused them to find new jobs, the number of workers near the margin declines, and the probability of destruction falls for an extended period. Episodes of job destruction tend to be concentrated in time, because each episode depletes the stock of vulnerable jobs. The next episode is less likely to occur until the gradual process of degradation builds up a new stock of vulnerable jobs, close to the shut-down margin.

\section{Model with Fixed Wage}

The model I consider here is the same as in the previous section, except for the following: workers are all paid a fixed wage w. Firms make unilateral decisions about separations. There is free entry of firms to the market. Searching workers encounter prospective employers at the rate $\phi$. As in the previous case, the encounter always results in a job, now because firms earn rents on their workers.

The firm associates a value $J_{i, t}$ with a filled job at productivity $\omega^{i}$. The current value is related to the discounted future value according to

$$
\left.J_{i, t}=\max \left\{\mathbb{E}_{t}\left[e^{-r_{t}} \mathbf{Q}^{i}-w+\mathbf{D}_{\pi} \mathbf{\mathbf { g } _ { , t + 1 }}+\pi J_{i+1, t+1}\right]\right], \gamma\right\}
$$


In equation 5.1, the firm compares its joint continuation value, $\left.E_{t}\left[e^{-r_{t}} \mathbf{\mathbb { d }}^{i}-w+\mathbf{D} \pi \mathbf{g}, t+1+\pi J_{i+1, t+1}\right]\right]$, to the breakup value, $\gamma$, and acts accordingly. The free-entry condition implies that firms do not value a vacant job; the breakup value is just the avoided investment cost, $\gamma$.

In the steady state, workers remain in their jobs until they have progressed through a critical number of productivity degradations, $k$. The cutoff value, $k_{s}$ is the one for which the corresponding search value satisfies

$$
\omega^{k} \leq r \gamma+w \leq \omega^{k-1}
$$

that is, current output $\omega^{k-1}$ exceeds the opportunity cost of the capital, $r \gamma$ plus the wage, $w$, at this level of productivity, but will fall short after the next degradation lowers productivity to $\omega^{k}$. The wage replaces the opportunity cost of the worker's time, $r U$-compare equation 5.2 to 4.9 .

If the fixed wage in the second model exceeds the opportunity cost as determined in the first model, equation 5.2 shows that the cutoff level of productivity will be higher ( $k$ will be lower) and thus unemployment will be higher in the steady state.

The two models also differ sharply in their responses of steady-state unemployment to the interest rate. Equation 5.2 shows that $k$ and thus unemployment will be unambiguously higher for a higher interest rate in the fixed-wage model. The unilateral employment decisions made by firms in the fixed-wage model do not incorporate the countervailing effects from higher unemployment that result from efficient separation decisions.

Figure 3 shows the impulse response functions for the fixed-wage model, with the wage held at $w=0.5$. Though the time patterns of both functions are similar to those in Figure 2 for the efficient case, the magnitudes of the responses 
are vastly higher. Employment is far more fragile in the fixed-wage case, where employers fire workers without considering the resulting search costs.
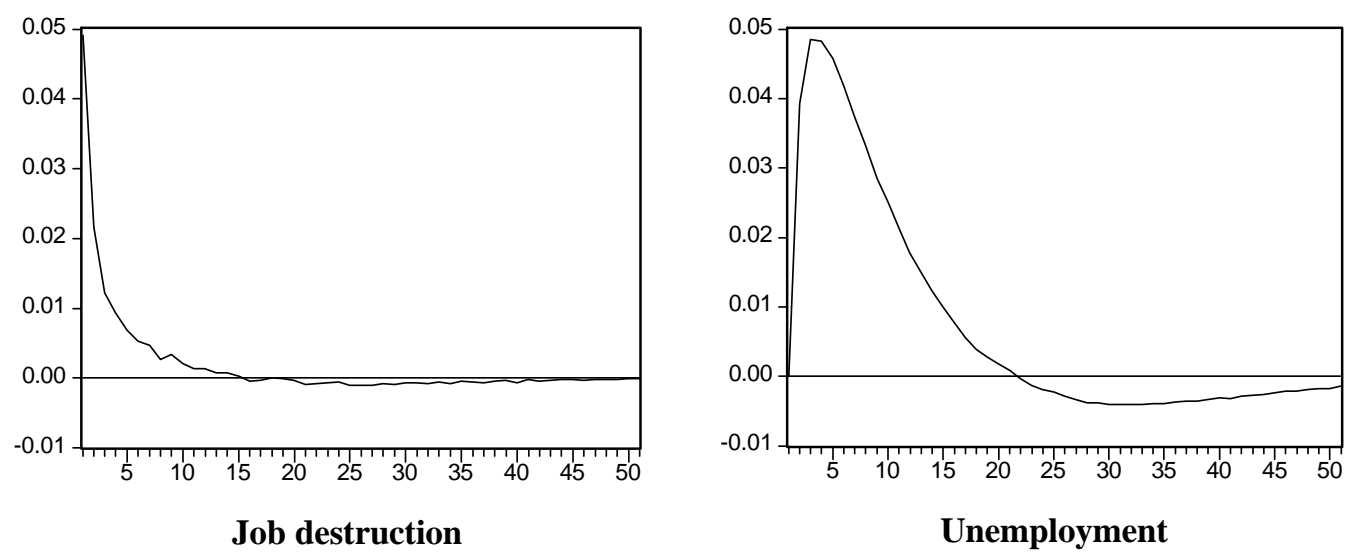

Figure 3. Impulse Response Functions of Job Destruction and Unemployment to a Real Interest Rate Innovation, Fixed Wage Case

In principle, it might be possible to shed light on the question of the efficiency of separations by comparing the estimated response of job destruction to financial impulses to the theoretical functions derived in this section. The difference between the magnitudes of the responses for efficient and fixed-wage employment arrangements seems large enough to create some hope. But, as the next section shows, fundamental identification issues relating to general equilibrium stand in the way of measuring the actual impulse response function. The data are fully consistent with either strong or weak responses of job destruction to financial impulses. 


\section{Measuring the Response of Job Destruction and Inventories to Impulses in the Expected Real Interest Rate}

I take the time period to be a quarter and use the 6-month commercial paper rate as the nominal interest rate, the change in the GDP deflator as the inflation rate, and the Davis-Haltiwanger measures of quarterly job destruction in manufacturing durables and non-durables. Table 1 documents the relation between the interest rate and job destruction and inventory changes. Within the first quarter, the responses are always in the opposite direction from those expected if the interest-rate changes are exogenous. Job destruction falls and inventory investment rises. In three of the four cases, the relation is statistically unambiguous. There is a strong case that changes in economic activity from other sources are inducing changes in the interest rate within the quarter.

\begin{tabular}{lcccc}
\hline \hline \multirow{2}{*}{ agg } & \multicolumn{2}{c}{ Durables } & \multicolumn{2}{c}{ Non-durables } \\
\cline { 2 - 5 } 0 & Destruction & Decumulation & Destruction & Decumulation \\
\hline \multirow{4}{*}{1} & -0.493 & -0.86 & -0.273 & -0.07 \\
& $(0.106)$ & $(0.23)$ & $(0.117)$ & $(0.26)$ \\
2 & 0.169 & -1.17 & 0.127 & -0.50 \\
& $(0.075)$ & $(0.27)$ & $(0.093)$ & $(0.27)$ \\
& 0.280 & 0.61 & 0.092 & 0.10 \\
3 & $(0.052)$ & $(0.29)$ & $(0.109)$ & $(0.30)$ \\
& 0.266 & 0.56 & 0.172 & .83 \\
4 & $(0.083)$ & $(0.22)$ & $(0.095)$ & $(0.30)$ \\
& 0.073 & 1.19 & 0.004 & -0.07 \\
& $(0.067)$ & $(0.26)$ & $(0.095)$ & $(0.21)$ \\
\hline \hline
\end{tabular}

Table 1. Regression Coefficients for Current and Lagged Interest Rates.

Dependent variables are the Davis-Haltiwanger job destruction rates and the ratio of the negative of real inventory changes to real inventory stocks. Right-hand variables are a constant, current and four lagged values of the 6-month commercial paper rate, and, for job destruction, a dummy for the first quarter of the year. Standard errors in parentheses were calculated by the Newey-West HAC procedure. The sample covers $1972,2^{\text {nd }}$ quarter through $1988,4^{\text {th }}$ quarter for job destruction and $1959,1^{\text {st }}$ quarter through $1996,4^{\text {th }}$ quarter, for inventory decumulation. 
Most of the coefficients on the lagged values of the interest rate have signs corresponding to the case of exogenous changes in the interest rate. The sum of the coefficients for the four lagged values of the interest rate has that sign in all cases and its magnitude is statistically unambiguous in all cases but non-durables inventory changes. The relations shown in Table 1 could be interpreted as the combined effect of a speedy influence that pushes interest rates and job destruction in opposite directions and a slower influence that pushes them in the same direction. The second is the one embodied in the models of the previous two sections, where exogenous increases in interest rates cause job destruction and inventory runoffs. The first involves the response of interest rates to other impulses, such as a shock to technology that lowers job destruction and raises the interest rate at the same time.

Two steps are required to consider the issue more formally. First is to move from the nominal interest rate to the expected real interest rate. Second is to develop an identified model containing both the positive feedback from other sources of variation in economic activity to the interest rate and the mechanism based on exogenous changes in the real interest rate considered earlier in this paper.

\section{A. Innovations in the Expected Real Interest Rate}

I use a model of the joint distribution of the nominal interest rate, the rate of inflation, and job destruction to infer innovations in the real rate and to measure their effects on job destruction. I let

$$
y_{t}=
$$


where $n_{t}$ is the nominal interest rate, $\pi_{t}$ is the rate of inflation, and $d_{t}$ is the job destruction rate. I assume that $y_{t}$ obeys a VAR,

$$
y_{t}=A(L) y_{t-1}+\varepsilon_{t}
$$

The real interest rate is

$$
r_{t}=n_{t}-E_{t} \pi_{t+1}
$$

Note that

$$
E_{t} \pi_{t+1}=A^{(2)} y_{t}
$$

where $A^{(2)}(L)$ is the second row of $A(L)$. Let

$$
\begin{aligned}
\tilde{y}_{t} & =R(L) y_{t}
\end{aligned}
$$

where

$$
R(L)=I-\underbrace{(L)}_{0}
$$

Let $\widetilde{\varepsilon}_{t}$ be the innovations in $\tilde{y}_{t}$ and let $R_{0}=R(0)$ : 


$$
\begin{aligned}
\tilde{\varepsilon}_{t} & =\tilde{y}_{t}-E_{t-1} \tilde{y}_{t} \\
& =R_{0} \longrightarrow-E_{t-1} y_{t} \mathbf{Q} \\
& =R_{0} \varepsilon_{t}
\end{aligned}
$$

because

$$
y_{t-i}=E_{t-1} y_{t-i} \text { for all } i>0
$$

To estimate the response of job destruction to innovations in the expected real interest rate, it is useful to deal with transformed contemporaneous variables,

$$
\hat{y}_{t}=R_{0} y_{t}
$$

The first element of the transformed vector is the nominal rate less the part of the future rate of inflation forecasted by current inflation and other variables. The second and third elements are the inflation rate and job destruction. The transformed vector obeys a vector autoregression,

$$
\begin{aligned}
\hat{y}_{t} & =R_{0} A(L) R_{0}^{-1} \hat{y}_{t-1}+\widetilde{\varepsilon}_{t} \\
& =\hat{A}(L) \hat{y}_{t-1}+\widetilde{\varepsilon}_{t}
\end{aligned}
$$

Note that the transformed variables $\hat{y}_{t}$ obey a VAR of the same order as $y_{t}$, whereas the variables $\tilde{y}_{t}$ have a VAR representation of infinite order.

\section{B. Identification}

The vector autoregression implies a moving-average relation between the two key variables and two of the impulses, a subset of the full moving-average representation of the model, 


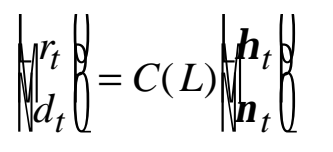

where $C(L)$ is the matrix of impulse response functions, $\eta_{t}$ is an innovation considered to be a financial shock, and $v_{t}$ is another innovation considered to be an output shock resulting from technology or other forces.

The complete set of impulse response functions of a three-variable VAR is three parameters short of identification. My identifying assumptions are:

1. The financial shock does not affect inflation within the same quarter,

2. The output shock does not affect inflation within the same quarter, and

3. The immediate positive effect of the output shock on the expected real interest rate is a known multiple, $\rho$, of the immediate negative effect of the output shock on job destruction.

The third assumption can be stated as

$$
C_{1,2}(0)=-\rho C_{2,2}(0)
$$

The coefficient $\rho$ is the number of percentage points of effect on the expected real interest rate from the output shock per percentage point of effect on the job destruction rate.

Although this paper has avoided the difficult issue of general equilibrium up to this point, it is impossible to interpret the empirical evidence without dealing with the general-equilibrium issue encapsulated by this identifying condition. There is a strong presumption that $\rho$ is positive-when a non-financial event raises output, it raises the expected real interest rate as well. The empirical results presented at the beginning of this section support that hypothesis. I will proceed by estimating the impulse response functions for two reasonable values of $\rho, 0.5$ and 1.5 . 
In practice, the method developed in this section involves fitting a vector autoregression to the data on the nominal interest rate, the rate of inflation, and the rate of job destruction. The VAR yields the coefficients of the inflation prediction equation based on the immediate lagged values of the other variables, as required by the data transformation in equation 6.9. Then I re-run the same VAR as equation $6.10{ }^{4}$ I obtain the impulse response functions corresponding to the standard Choleski factorization with the variables in the order of inflation, expected real interest rate, and job destruction. Finally, I calculate the impulse response functions corresponding to my identifying conditions by multiplying the reported functions by an orthonormal matrix that embodies the identifying condition. ${ }^{5}$

\footnotetext{
${ }^{4}$ This is not a two-stage estimation process in any sense. Re-running the VAR is just a convenient way to carry out calculations that could be done in one round of estimation. The results are numerically the same.

${ }^{5}$ The computational appendix available from http://www.stanford.edu/ rehall/ shows the details.
} 


\section{Results}

A. Job Destruction

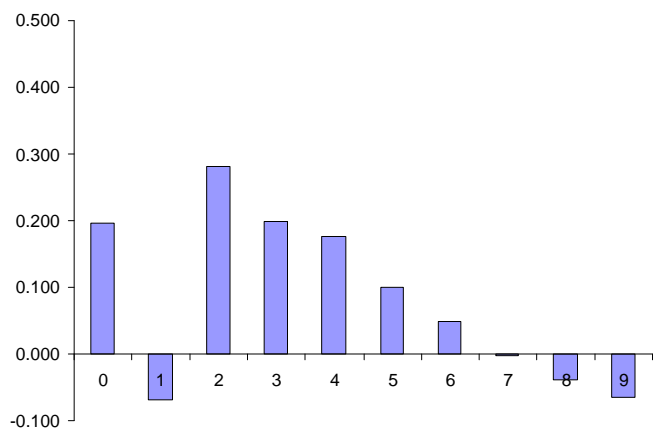

Durables, smaller effect of output on expected real interest rate

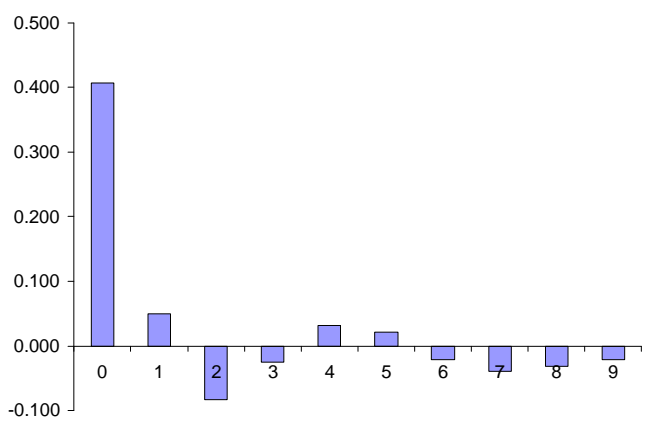

Non-durables, smaller effect of output on expected real interest rate

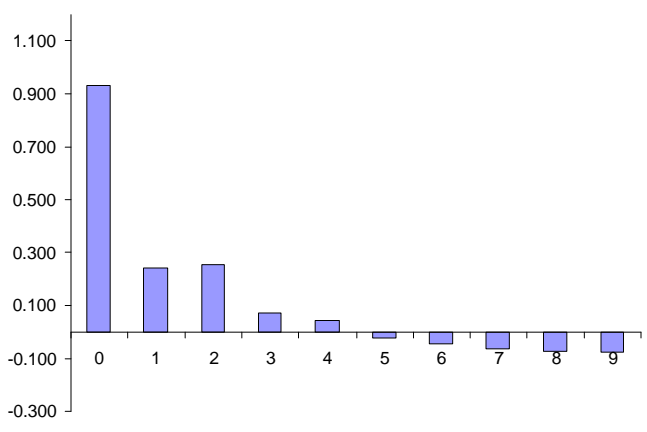

Durables, larger effect of output on expected real interest rate

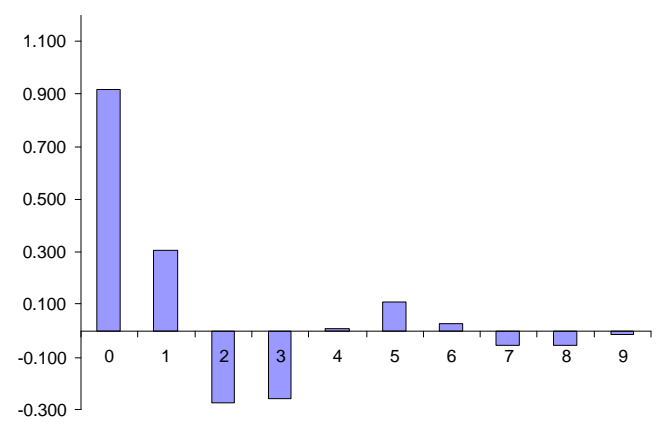

Non-durables, larger effect of output on expected real interest rate

\section{Figure 4. Estimated Response of Job Destruction to a Financial Impulse}

Figure 4 shows the response of job destruction to a positive impulse in the interest rate, estimated by the method developed in the previous section. The results on the left side are for $\rho=.5$; that is, an output shock that raises job destruction by 1 percentage point lowers the expected real interest rate by 0.5 percentage points. The results on the right side are for $\rho=1.5$. The values are normalized to show the number of percentage points of job destruction caused by 
an impulse whose immediate effect is to raise the expected real interest rate by one percentage point. Notice that the scales are different for the two values of $\rho$.

All four plots show a strong positive contemporaneous effect of the financial impulse on job destruction. The plot on the top right, for stronger effects on durables job destruction running from the output impulse to the interest rate, look quite similar to those from the theoretical model in Figure 3. These plots show that the observed joint distribution of job destruction and the interest rate are consistent with the mechanism developed in this paper. They could not be said to demonstrate the importance of the mechanism, because they rest on the identifying condition that there is another impulse-the output or technology shock-that causes the expected real interest rate to move in the opposite direction from job destruction. The regression results in Table 1 show that the contemporaneous correlation of the interest rate and job destruction is actually negative. I interpret that finding as showing the importance of the output shock, not as evidence against the effect of the financial shock. But that interpretation rests on the untestable prior belief that there is an output shock with a positive effect on the expected real interest rate. These issues cannot be resolved without the development of a full general-equilibrium model.

\section{B. Employment Reductions}

The rate of decline of employment is reasonably closely correlated with job destruction and is available for all sectors of the economy. Figure 5 shows the response of employment declines to innovations in the expected real interest rate, estimated by the method outlined in the previous section. The dependent variable is minus the percent change in employment. The responses are for the smaller hypothesized response of the expected real rate to the output shock $(\rho=0.5)$. 


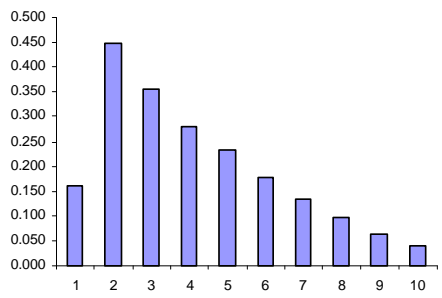

Durables

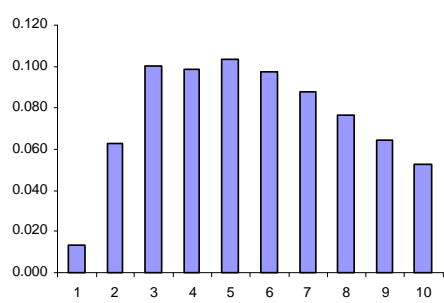

Wholesale trade

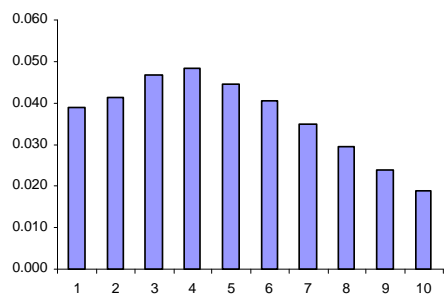

Services

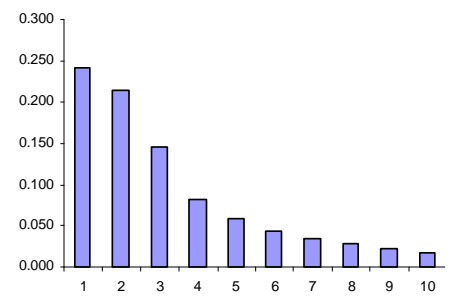

Non-durables

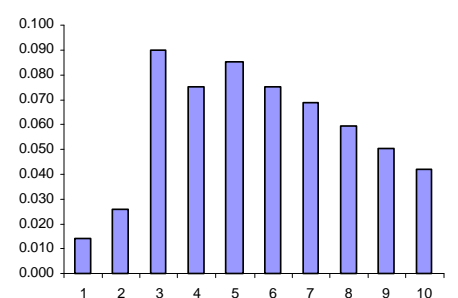

Retail trade

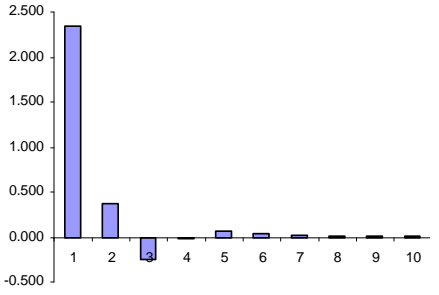

Mining

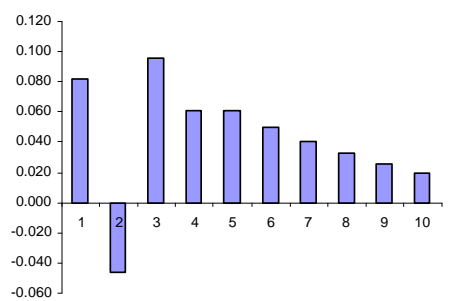

Transportation

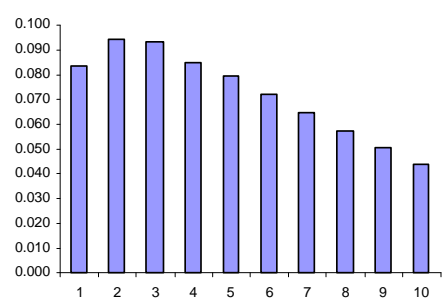

Finance, Insurance, Real estate

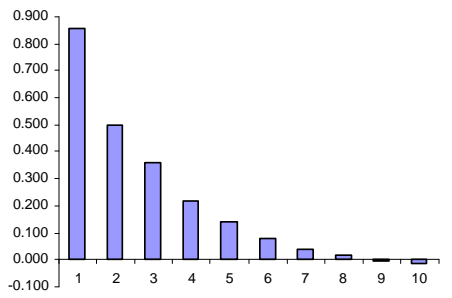

Construction

Figure 5. Responses of Employment Decline to Innovations in the Expected Real Interest Rate

All 9 industries show impulse responses similar to the one derived from the theoretical model. A surprise increase in the expected real interest rate triggers an immediate decline in employment, followed by small declines spread over the future. In durables and construction, the effect turns negative over the 10 quarters shown in the plots in Figure 5. 


\section{Inventory Decumulation}

Figure 6 shows the responses of inventory decumulation to an impulse in the expected real interest rate. Again, these responses are measured under the first of the two identifying assumptions stated in the previous section, with $\rho=0.5$.

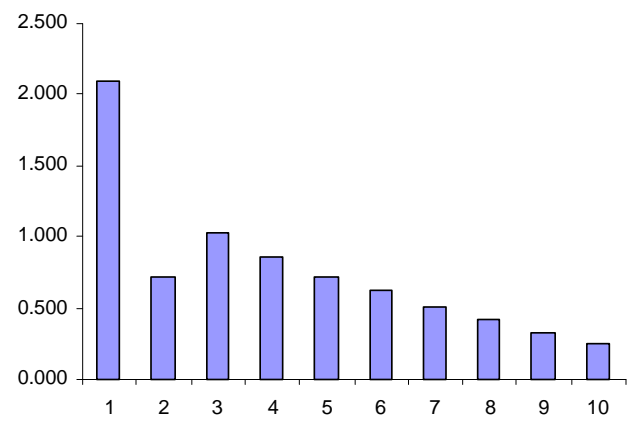

Durables

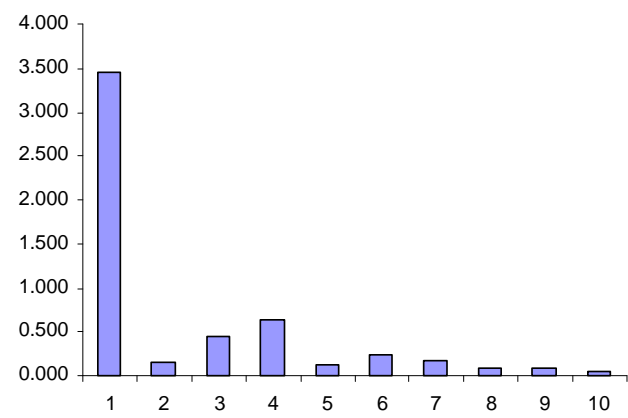

Wholesale trade

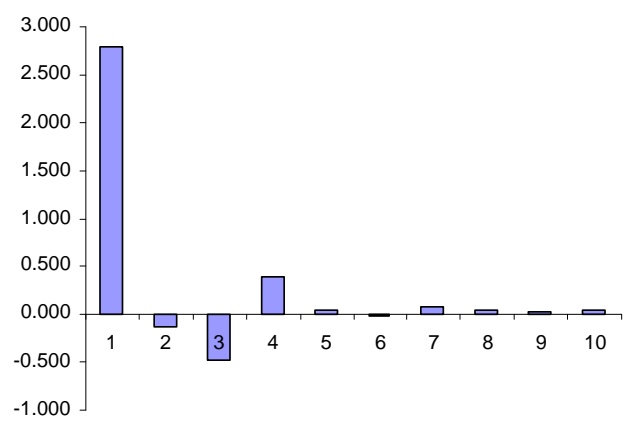

Non-durables

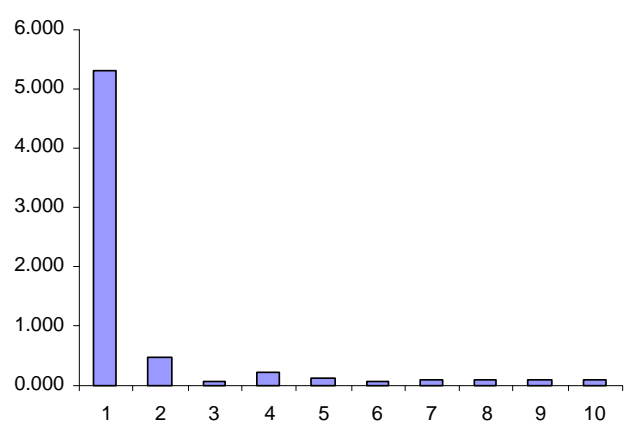

Retail trade

Figure 6. Responses of Inventory Decumulation to Innovations in the Expected Real Interest Rate

In all four inventory-holding sectors, the immediate burst of inventory decumulation predicted by the model is evident in the plots. The immediate dynamics for inventories are similar to job destruction. In durables, inventory decumulation continues in succeeding quarters, along with job destruction. But in 
the other three industries, inventory decumulation virtually ceases one quarter after the real interest rate impulse, contrary to the findings for job destruction. In the model developed earlier in the paper, the dynamics of job destruction and inventory decumulation are the same. Of course, the findings for inventory decumulation are tentative in the same way as those for job destruction and employment declines - they rest on an assumed identifying condition.

\section{Concluding Remarks}

There are good reasons to believe that events that cause increases in the expected real interest rate also cause job destruction along the lines of the model developed in this paper. Let me return to an issue raised in the introduction: Could it be that high interest rates reduce product demand, so that the observed association arises not from the influence of the discount rate on shutdown decisions, but rather from the influence on demand? In a competitive generalequilibrium model, the state of demand is conveyed to the firm by the price of the firm's product. Thus, coherent ideas about product demand relate to changes in the relative prices of products. There are two types of relative prices that might be considered in this context. First is the price of output today relative to the price of output next period. That price is the interest rate and has been the subject of this paper. In that sense, the financial effects considered here could be called demand effects.

The second is the relative price of two kinds of products. In particular, the relative price of durables and non-durables could be volatile in a model where the two types of products are not close substitutes in production, that is, in a twosector model. An exogenous decline in the price of durables relative to nondurables would cause job destruction in durables in a two-sector model. But the 
other side of the coin is that the price of non-durables would rise relative to durables, which would reduce job destruction in non-durables. So forces that cause changes in relative prices induce reallocation of labor from one sector to another. They cannot cause job destruction in every sector.

The subject of this paper is aggregate job destruction and the investigation of forces that could cause job destruction in all sectors. It remains an interesting and unresolved issue whether forces other than exogenous increases in interest rates are likely to cause widespread job destruction. But I believe it is fair to conclude that mechanisms operating through demand in the sense of relative product prices are not the whole answer to the puzzle of recessions, where jobs are destroyed everywhere. The following view does not survive scrutiny within a general-equilibrium model: Adverse financial shocks reduce the demand for interest-sensitive durable goods, and the effects quickly radiate to all the sectors of the economy.

The model in this paper can co-exist peacefully within a two-sector model where the effect of financial shocks is greater in the durables sector than elsewhere. But there has to be enough job destruction in non-durables from the intertemporal mechanism developed here to overcome the stimulus to nondurables employment from the atemporal relative-price effect.

What causes the increases in the real interest rate that drive aggregate job destruction in the view developed in this paper? The volatility of interest rates remains largely a mystery in modern general-equilibrium macroeconomics. Monetary policy seems to be an important part of the story. Sharp increases in the rate often occur in times of monetary tightening-1969, 1974, 1980, and 1982. There appears to be a substantial role for the monetary authority to trigger a burst of job destruction and inventory liquidation by stepping hard on the monetary brake. Explanation of this role requires an understanding of monetary nonneutrality, an elusive subject. 


\section{References}

Caballero, Ricardo J. and Mohamad L. Hammour. 1996a "On the Timing and Efficiency of Creative Destruction" Quarterly Journal of Economics. 111805-852. August.

Caballero, Ricardo J. and Mohamad L. Hammour. 1996b. "The 'Fundamental Transformation' in Macroeconomics" American Economic Review Papers and Proceedings 86:181-186. May.

Caballero, Ricardo J. and Mohamad L. Hammour. 1997. "Jobless Growth: Appropriability, Factor Substitution, and Unemployment" presented to the Carnegie-Rochester Public Policy Conference. April.

Davis, Steven J., and John Haltiwanger. 1990. "Gross Job Creation and Destruction: Microeconomic Evidence and Macroeconomic Implications" NBER Macroeconomics Annual 5: 123-168.

Davis, Steven J., John C. Haltiwanger, and Scott Schuh. 1996. Job Creation and Destruction. Cambridge: MIT Press.

Diamond, Peter A. 1982a. "Wage Determination and Efficiency in Search Equilibrium." Review of Economic Studies 29: 217-227

Diamond, Peter A. 1982b. "Aggregate Demand Management in Search Equilibrium." Journal of Political Economy 90: 881-894

Hall, Robert E. 1995. “Lost Jobs” Brookings Papers on Economic Activity 1: 221273

- 1997. Discussion of Caballero-Hammour at CarnegieRochester Conference. April.

. 1998a. "Labor Market Frictions and Employment Fluctuations"

in John Taylor and Michael Woodford (eds.) Handbook of Macroeconomics. New York: North-Holland. Forthcoming. . 1998b. "The Concentration of Job Destruction" in preparation.

Hall, Robert E., and Edward P. Lazear. 1984. "The Excess Sensitivity of Layoffs and Quits to Demand." Journal of Labor Economics 2: 233-257 
Hansen, Lars Peter, and Ravi Jagannathan. 1991. "Implications of Security market Data for Models of Dynamic Economies" Journal of Political Economy, vol. 99, pp. 225-262.

Hart, Oliver. 1983. "Optimal Labour Contracts under Asymmetric information: An Introduction." Review of Economic Studies. 50:3-35.

Hashimoto, Masanori, and Ben Yu. 1980. "Specific Capital, Employment Contracts, and Wage Rigidity." Bell Journal of Economics 11: 536-549

Hosios, Arthur. 1990. "On the Efficiency of Matching and Related Models of Search and Unemployment" Review of Economic Studies 57:279-298, April.

Kahn, Charles, and Gur Huberman. 1988. "Two-Sided Uncertainty and 'Up-orOut' Contracts." Journal of Labor Economics 6: 423-444.

Kreps, David M. 1981. "Arbitrage and Equilibrium in Economies with Infinitely Many Commodities" Journal of Mathematical Economics 8: 15-35.

Mirrlees, James. 1971. "An Exploration in the Theory of Optimum Income Taxation” Review of Economic Studies 38:175-208.

Mortensen, Dale. 1982. "Property Rights and Efficiency in Mating, Racing, and Related Games" American Economic Review 72: 968-979.

Ramey, Garey, and Joel Watson. 1997. "Contractual Fragility, Job Destruction, and Business Cycles." Quarterly Journal of Economics 112:873-912, August. 